\title{
Optimization Model of Total Phenolic Compounds in Zingiber Officinale via Ultrasound- Assisted Extraction Technique
}

\author{
Adilah Anuar ${ }^{1 *}$ Tan Jing $\mathrm{Yi}^{2}$ and Mohd Azrie Awang ${ }^{3}$ \\ $1,2 *$ Faculty of Chemical Engineering Technology \\ Faculty of Chemical Engineering Technology, Universiti Malaysia Perlis, Kampus UniCITI Alam, \\ Sungai Chuchuh, 02100 Padang Besar,Perlis Malaysia \\ ${ }^{3}$ Faculty of Food Science and Nutrition, \\ Universiti Malaysia Sabah, Jalan UMS, 88400 Kota Kinabalu, Sabah Malaysia
}

\begin{abstract}
Ginger (Zingiber Officinale) as a medicinal herb is frequently neglected for other possible applications and usually only be consumed as spices. It shows unpredictable potentialities in both food and pharmaceutical industries. This study aims to provide the comprehensive view on the optimization model of extraction of polyphenols from ginger as well as the antioxidant and antimicrobial capacity of ginger extracts. Extraction parameters screening of various parameters assessed the influence of these parameters against the efficiency of recovering polyphenols from ginger. This includes the extraction temperature $\left(60-80{ }^{\circ} \mathrm{C}\right)$, quantity of spice which represent the concentration of ginger $(200-600 \mathrm{mg} / 20 \mathrm{ml}$ solvent) and the solvent concentration $(60-80 \%)$ for the extraction of polyphenols from ginger. The optimum parameters were found to be at $80^{\circ} \mathrm{C}, 468 \mathrm{mg} / 20 \mathrm{ml}$ solvent and the solvent concentration at $70 \%$ and the extraction time was found to have minimal influence on the extraction process. The total yield of phenolic content under optimum condition were found to be at $22.333 \pm$ $0.2462 \mathrm{mg} \mathrm{GAE} / \mathrm{g}$ of dry weight of ginger extract.
\end{abstract}

Key words: Zingiber Officinale, extraction,polyphenol,optimization

\section{INTRODUCTION}

With the outbreaks of infectious disease rising all around the world and direct responsibility of infectious disease which contributes for nearly $25 \%$ of mortality rate globally [1]. Viruses and bacteria are known as most common inducer of the infectious disease. In the same way, microbial threatened not only global health but as well as the food security today. Henceforth, there are more and more studies and research on the use of natural herbs in lieu of commercially available antibiotics and synthetic food preservatives. In fact, the usage of natural herbs and spices to fight spectrum of microbial threats can be traced back even before antibiotics and chemical derived food preservatives was discovered and applied. Ginger is defined as an ayurvedic which is one of those natural herbs which possess the necessary bioactive compound that have effect in inhibiting the microbial growth. The ginger is a member of the Zingiberaceae family and Zingiber genus of plant, and its scientific name is Zingiber officinale ( $Z$. officinale). The ginger is a perpetual plant with thick tuberous rhizomes. A major part of ginger which is consumed is known as the rhizome. It is a commonly consumed dietary condiments, spices and the rhizome part is also used extensively as herbal medicine for a long time by Chinese and Indians [2]. The Chinese and Indians are known to utilize ginger for over 5000 years to cure abundant of ailments [3]. The ginger has been discovered to possess numerous biological activities such as anti-inflammatory, antioxidant [4], anticancer [5] and antimicrobial activities [6]. The bioactivities of the ginger make it capable to avert and control several diseases, for instance neurodegenerative diseases [7] cardiovascular diseases [8], obesity, obesity mellitus [9] chemotherapy-induced nausea and emesis [10], and respiratory disorders [11]. Due to the unbranched 
alkyl chain, gingerols are identified as analogous phenolic ketones and subsist as 6, 8, and 10-gingerols among all the bioactive compounds found in ginger. These polyphenols possess bioactive compounds which have significant effect in treating various diseases. The methodology chosen to complete this review is the Ultrasound-Assisted Extraction (UAE). UAE is the first choice chosen for this extraction process as the UAE method possess several interesting advantages over the conventional method such as the time required for extraction is faster using UAE. Next, the UAE is generally safer as it does not require high pressure. Moreover, the whole procedure is simpler and less prone to contamination. However, there are some parameters that need to be extra cautious when adopting UAE method which is the particle size and the ultrasonic probe surface ageing problem. The optimal extraction condition of ginger is study in this review to achieve the polyphenols maximum yield per gram of ginger. DPPH assay is used to determine the antioxidant activity of the extracted polyphenols using optimizes parameters. This is to maximize polyphenols extraction from ginger with greater activity of antioxidant and find out the most profitable analytical model. Factors that enhancing the diffusivity and solubility will accelerate the extraction process. The extraction efficiency will be influenced by the choice of extraction solvent, the solvent-to-solid ration $(\mathrm{mg} / 20 \mathrm{ml}$ solvent), particle size of ginger powder, the extraction temperature $\left({ }^{\circ} \mathrm{C}\right)$, solvent concentration $(\%)$ and the extraction duration (minutes). Generally, all the factors should be considered to get highest yield of the extraction. The extractive capability of phenolic components from ginger is considerably rely on the type of solvent. The solubility level of phenolic compounds in different solvent is different. To extract the phenolic compounds, a ratio of solid-to-solvent which is high is found to be favorable for the extraction. The concentration gradient amongst the solid and the solvent is the driving force for mass transfer and the results are accordant with mass transfer principle.In UAE, there is a significant repercussion of temperature on the yield of extraction. In overall, increases in extraction yields of the phenolic compounds caused by an increase in temperature. There are various factors that correlates with extraction temperature such as the ruptures of matrix bonds being initiated, increase of the solvent diffusion rate, solubility of compound, decrease in tension and viscosity of the solvent and mass transfer [12]. To evaluate the effects of three independent variables, the extraction temperature (X1: $\left.40-80{ }^{\circ} \mathrm{C}\right)$, extraction solvents concentration (X2: 50\%-90\%), quantity of spice (X3: $200-1000 \mathrm{mg} / 20 \mathrm{ml}$ solvent) and time (X4: $0.5-1.5 \mathrm{~h})$ on the extract properties. The UV-vis spectrophotometer is used to measure the TPC, TFC and DPPH radical scavenging activity of the ginger extract. In this review, the action mechanisms of ginger are summarized. The total flavonoid and phenolic contents of ginger is investigated and the optimum conditions for extraction of ginger is analyzed.

\section{EXPERIMENT}

\section{Ultrasound-Assisted Extraction (UAE)}

The UAE was used for the extraction method with liquid solvents used on specimens in solid matrices. The UAE was carried out by following the quantity of spices and the amount of solvents that were set earlier. Extraction was conducted by mixing the powdered ginger with $20 \mathrm{ml}$ of extract solvent in a $100 \mathrm{ml}$ conical flask with different extract parameters. The contents in of the conical flask were subjected to ultrasonication at various pre-set extract parameters. The samples were filtered by cotton for the first time, followed by the transferring of the supernatant to a centrifuge tube and centrifugation at $8{ }^{\circ} \mathrm{C}, 3000 \mathrm{~g}$ for 30 minutes. The resultant supernatant was collected and went through TPC.

\section{Screening of Extraction Solvent Type}

Screening of solvent types was carried out by using three types of solvent, which were distilled water, 50\% methanol and 50\% ethanol. Solvent screening was carried out in an ultrasound water bath with constant power. $600 \mathrm{mg}$ of powdered ginger was extracted in 20 $\mathrm{ml}$ of different solvents under two different temperatures, which were $30{ }^{\circ} \mathrm{C}$ and $50{ }^{\circ} \mathrm{C}$. The extraction was carried out in triplicate, and the TPC were evaluated using the Folin-method to determine the type of solvent for further study in optimization of the extract parameters.

\section{Screening of Extraction parameters}

In the screening of parameters, the extraction parameters, which were quantity of spice, extraction solvent concentration, and extraction temperature, were evaluated. The screening of extraction parameters was carried out by the one factor at a time (OFAT) method, which uses one factor variable with a holding constant of the other two parameters. The extraction parameters were tested between $200 \mathrm{mg} / 20 \mathrm{ml}$ solvent and 1000 $\mathrm{mg} / 20 \mathrm{ml}$ solvent for spice quantity, 50-90 \% ethanol 
concentration, and $40{ }^{\circ} \mathrm{C}-80 \quad{ }^{\circ} \mathrm{C}$ for extraction temperature.

\section{RESULT AND DISCUSSION}

\section{Screening of Extraction Parameters}

The yield of polyphenols can be affected by the solvent type, as different solvent has different polarity. Ethanol is commonly used as a solvent when polyphenol extraction is carried out, as it is safe for human consumption too. Methanol, on the other hand, is more efficient when polyphenols with a lower molecular weight are used [13]. However, there was no record of any previous research on the screening of different types of extraction solvents for ultrasound assisted extraction of ginger rhizome. The solvent screening in this study was carried out under the same conditions of $600 \mathrm{mg} / 20 \mathrm{ml}$ of solvents for 30 minutes at $50{ }^{\circ} \mathrm{C}$. The variable parameter was the type of solvents, distilled water, $50 \%$ methanol, and $50 \%$ ethanol were used to determine the best solvents to produce the highest recovery of polyphenols in ginger. The quantitative analysis of TPC by various solvents recorded decreased in the following order: $50 \%$ aqueous ethanol, $50 \%$ aqueous methanol, distilled water, respectively.

Table 1. Quantitative analysis of ginger extract with different type of solvents.

\begin{tabular}{cc}
\hline Solvent Type & $\begin{array}{c}\text { Total Phenolic Content } \\
\text { (TPC) }(\mathrm{mg} \text { GAE/g) }\end{array}$ \\
\hline Distilled Water & $10.67 \pm 4.4746$ \\
Methanol & $14.00 \pm 2.5511$ \\
Ethanol & $15.33 \pm 0.8184$ \\
\hline
\end{tabular}

The extraction time was screened under the conditions of $600 \mathrm{mg}$ of ginger to $20 \mathrm{ml}$ of solvent, 50 ${ }^{\circ} \mathrm{C}$, and $50 \%$ ethanol; the results are tabulated in Table 2 . The screening of extraction time shows no obvious order from 10 minutes to 60 minutes. As elucidated by [14], extraction time was found to have a lower effect on phenolic compound recovery using ultrasound assisted extraction. This screening result can also be supported by the fact that the response surface plot results show a relatively insignificant effect of extraction time as compared to other extracting parameters [15]. Therefore, the extraction time was held constant at 30 minutes.
Table 2. Quantitative analysis of screening of extraction time.

\begin{tabular}{cc}
\hline $\begin{array}{c}\text { Extraction Time } \\
(\mathrm{min})\end{array}$ & $\begin{array}{c}\text { Total Phenolic Content } \\
(\mathrm{TPC})(\mathrm{mg} \text { GAE} / \mathrm{g})\end{array}$ \\
\hline 5 & $15.33 \pm 1.0472$ \\
10 & $16.67 \pm 1.6700$ \\
20 & $14.67 \pm 2.0873$ \\
30 & $18.67 \pm 0.5978$ \\
40 & $18.33 \pm 1.1811$ \\
50 & $16.67 \pm 1.0000$ \\
60 & $18.00 \pm 0.3300$ \\
\hline
\end{tabular}

The solid to solvent ratio will influence the ultrasound assisted extraction due to its surface area and mass transfer during the diffusion process [16]. Theoretically, a higher solid to solvent ratio will increase the extraction of polyphenols in common consent [17]. The screening of the quantity of spice was carried out under conditions of $50{ }^{\circ} \mathrm{C}, 50 \%$ ethanol, and 30 minutes. The yield of TPC increases significantly from $200 \mathrm{mg} / 20 \mathrm{ml}$ solvent to $400 \mathrm{mg} / 20$ $\mathrm{ml}$ solvent and the trend of the graphs gradually declines from $400 \mathrm{mg} / 20 \mathrm{ml}$ solvent to $800 \mathrm{mg} / 20 \mathrm{ml}$ solvent and there is a slight rise in $1000 \mathrm{mg} / 20 \mathrm{ml}$ solvent. An equilibrium constant trend was observed from $600 \mathrm{mg} / 20 \mathrm{ml}$ solvent to $1000 \mathrm{mg} / 20 \mathrm{ml}$ solvent.

Table 3. Quantitative analysis of screening of quantity of spice.

\begin{tabular}{cc}
\hline $\begin{array}{c}\text { Quantity of Spice } \\
(\mathrm{mg} / 20 \mathrm{ml} \text { solvent })\end{array}$ & $\begin{array}{c}\text { Total Phenolic Content } \\
(\mathrm{TPC})(\mathrm{mg} \text { GAE/g })\end{array}$ \\
\hline 200 & $15.00 \pm 0.9909$ \\
400 & $17.50 \pm 0.7238$ \\
600 & $15.33 \pm 2.7372$ \\
800 & $12.25 \pm 1.3987$ \\
1000 & $16.20 \pm 0.4784$ \\
\hline
\end{tabular}

The hydroalcoholic mixtures reportedly enhanced the extraction efficiency. Water not only increases the contact surface, but it also plays a role as a swelling agent in the plant matrix, and ethanol can incite the bond breaking between solutes and matrix [17]. The screening of ethanol concentration was carried out with the holding constant of the quantity of spice at $600 \mathrm{mg} / 20 \mathrm{ml}$ of solvent, time at 30 minutes and temperature at $50{ }^{\circ} \mathrm{C}$. The trend of the TPC graph shows a gradual increase with the variation of ethanol concentration from $50 \%$ to $70 \%, 70 \%$ ethanol has the 
highest TPC of $18.20 \pm 0.9923 \mathrm{mg} \mathrm{GAE} / \mathrm{g}$ and decreases gradually for the subsequent concentrations.

Table 4. Quantitative analysis of Solvent Concentration.

\begin{tabular}{cc}
\hline $\begin{array}{c}\text { Solvent } \\
\text { Concentration (\%) }\end{array}$ & $\begin{array}{c}\text { Total Phenolic Content } \\
\text { (TPC) (mg GAE/g) }\end{array}$ \\
\hline 50 & $9.67 \pm 0.4950$ \\
60 & $15.33 \pm 1.3654$ \\
70 & $18.20 \pm 0.9923$ \\
80 & $17.90 \pm 1.8520$ \\
90 & $13.00 \pm 1.7583$ \\
\hline
\end{tabular}

The extraction temperature has a similar theoretical assumption as the quantity of spice. A higher temperature accelerates the breaking of matrix bonds, increasing the mass transfer rate and diffusion rate of solvent as well as the solubility of bioactive compounds. The viscosity and tension of the solvent are also reduced with the increase of temperature during extraction [14]. The denaturation of polyphenols at high temperatures should be considered, thus too high of a temperature is not recommended. The trend in screening of extraction temperatures shows a steady rise of yield in polyphenols from $40{ }^{\circ} \mathrm{C}$ to $70{ }^{\circ} \mathrm{C}$ and then slightly dropped at $80{ }^{\circ} \mathrm{C}$ for TPC. The extraction temperature was tested under the conditions of 600 $\mathrm{mg} / 20 \mathrm{ml}$ of solvent, 30 minutes, and $50 \%$ ethanol. The extraction temperature range was set from $60{ }^{\circ} \mathrm{C}$ to $80{ }^{\circ} \mathrm{C}$ in future optimization extractions.

Table 5. Quantitative analysis of extraction temperature.

\begin{tabular}{cc}
\hline Temperature $\left({ }^{\circ} \mathrm{C}\right)$ & $\begin{array}{c}\text { Total Phenolic Content } \\
(\mathrm{TPC})(\mathrm{mg} \mathrm{GAE} / \mathrm{g})\end{array}$ \\
\hline 40 & $17.67 \pm 1.6817$ \\
50 & $19.44 \pm 0.9160$ \\
60 & $20.33 \pm 2.3400$ \\
70 & $21.33 \pm 1.4465$ \\
80 & $16.67 \pm 0.6600$ \\
\hline
\end{tabular}

The range of extraction parameters which were adopted for further optimization were set from the optimum range of graphs obtained from screening of extraction parameters. To further optimize ginger extract, raw material of $200 \mathrm{mg} / 20 \mathrm{ml}$ solvent, 400 $\mathrm{mg} / 20 \mathrm{ml}$ solvent, and $600 \mathrm{mg} / 20 \mathrm{ml}$ solvent were used, as well as extraction solvent concentrations of 60 $\%, 70 \%$, and $80 \%$, and extraction temperatures of 60
${ }^{\circ} \mathrm{C}, 70{ }^{\circ} \mathrm{C}$, and $80{ }^{\circ} \mathrm{C}$. The optimization process was carried out using the response surface method.

\section{Optimization of Ultrasonication for extraction of polyphenols}

For RSM, a three-level numerical factor with 3 three center points were executed. This study included three numerical factors, and the experimental data was evaluated to fit a quadratic statistical model. Conditions that were used were as follows: concentration of extraction solvent (20-80 \%), extraction time (10-30 minutes), temperature (30-70 $\left.{ }^{\circ} \mathrm{C}\right)$ and quantity of spice $(400-1200 \mathrm{mg} / 20 \mathrm{ml}$ solvent) [18]. These ranges were used as references in this study and screening of extraction parameters was carried out, so there were some modifications in the range of extraction parameters used for the optimization step in this study.

Table 6. Analysis of variance (ANOVA) table for TPC.

\begin{tabular}{llllll}
\hline Source & $\begin{array}{l}\text { Sum } \\
\text { of } \\
\text { squares }\end{array}$ & $\begin{array}{l}\text { df Mean } \\
\text { square }\end{array}$ & F-value P-value \\
\hline Model & 143.56 & 9 & 15.95 & $236.44<0.0001$ \\
A-Temperature & 10.67 & 1 & 10.67 & $158.18<0.0001$ \\
$\begin{array}{l}\text { B-Quantityof } \\
\text { Spice }\end{array}$ & 38.01 & 1 & 38.01 & $563.36<0.0001$ \\
$\begin{array}{l}\text { C-Solvent } \\
\text { Concentration }\end{array}$ & 23 & 1 & 23 & 340.9 & $<0.0001$ \\
AB & 0.2244 & 1 & 0.2244 & 3.33 & 0.1109 \\
AC & 5.54 & 1 & 5.54 & 82.19 & $<0.0001$ \\
BC & 22.24 & 1 & 22.24 & $329.73<0.0001$ \\
Lack of Fit & 0.3056 & 5 & 0.0611 & 0.7334 & 0.6632 \\
Pure Error & 0.1667 & 2 & 0.0833 & & \\
\hline
\end{tabular}

From Table 6, the quadratic interaction model of three parameters for TPC was evaluated. The quadratic parameters $\mathrm{AC}, \mathrm{BC}, \mathrm{A}^{2}, \mathrm{~B}^{2}$ and $\mathrm{C}^{2}$ were significant as $\mathrm{p}<0.05$. However, the parameter $\mathrm{AB}$ was not significant as the $\mathrm{p}$-value $>0.10$. All three of the extraction parameters were significant at $p<0.05$. The contribution of the quadratic model was significant, fitted the quadratic model for TPC in coded variables. 
The variable with the largest effect on TPC decreases in the order of the linear terms of quantity of spice (B) and solvent concentration $(\mathrm{C})$, followed by the interaction term of $\mathrm{BC}$. The lack of fit test measured the failure of the model, which denoted the data in the experimental domain at those points which were not included in the regression. The result showed-a lack of fit $\mathrm{p}$-value of $0.6632(\mathrm{p}>0.05)$ which indicates the experimental data fitted well to the model and is adequate to predict the TPC. The value of the determination coefficient $\mathrm{R}^{2}$ from the result obtained was 0.9967 and $\mathrm{R}_{\mathrm{adj}}{ }^{2}$ was 0.9925 . The $\mathrm{R}^{2}$ value indicates that the model is fitted at $99.67 \%$ of the variability of TPC, and the $\mathrm{R}_{\mathrm{adj}}{ }^{2}$ of $99.25 \%$ indicates that the data is adequately fit. This result shows that the experimental value and predicted values have a high correlation. In addition, the coefficient of variation $(\mathrm{CV})$ is a standard deviation in percentage of the mean. It is expected that a lower $\mathrm{CV}$ will have fewer residuals when compared to the predicted value. The result obtained was 1.60 , which suggests high reliability and preciseness of the experiment performed.

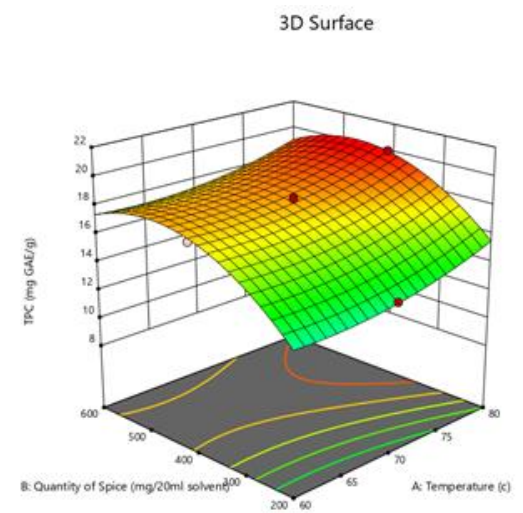

Figure $13 \mathrm{D}$ surface plot of extraction temperature and solvent concentration

\section{CONCLUSION}

In conclusion, this present study successfully adopted the one factor at a time (OFAT) method, the response surface method, and disc diffusion method to comprehensively assess the optimization model, antioxidant, and antibacterial study of ginger rhizome. The screening of extraction parameters concluded that the solvent type of ethanol results in the highest recovery of polyphenols in the extraction of ginger rhizomes, quantity of spice, solvent concentration, and extraction temperature were applied in the optimization model. The optimal extraction condition of quantity of spice, solvent concentration and extraction temperature
Figure 2 3D surface plot of extraction temperature and quantity of spice 3D Surface

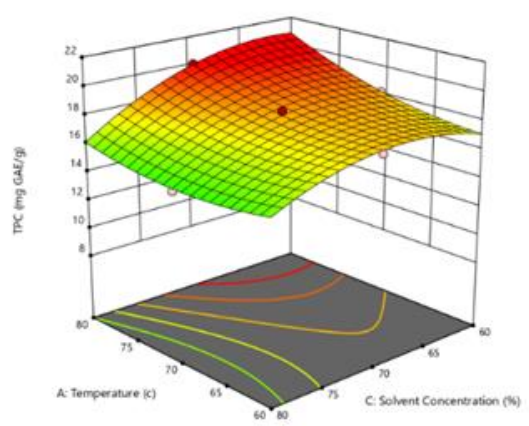

3D Surface

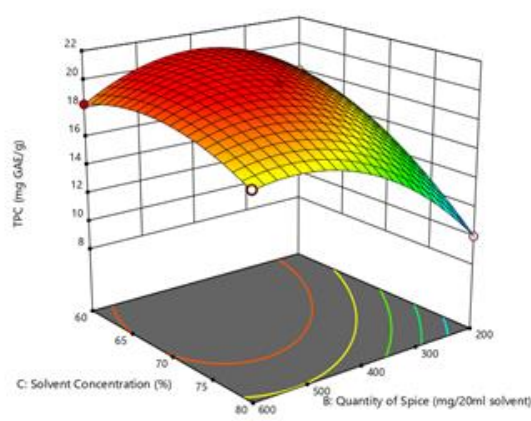

Figure 3 3D surface plot of quantity of spice and solvent concentration were $469 \mathrm{mg} / 20 \mathrm{ml}$ solvent, $70.77 \%$ and $80{ }^{\circ} \mathrm{C}$ with corresponding recovery of TPC at $22.333 \pm 0.2462$ $\mathrm{mg} / 20 \mathrm{ml}$ solvent. From the results, it can be concluded that these extraction parameters showed a significant effect on the recovery efficiency of TPC with a p-value less than 0.05. These results indicated the Central Composite Design (CCD) of Response Surface Methodology (RSM) was efficient in analysing the optimization of polyphenols in ginger rhizomes.

\section{ACKNOWLEDGMENTS}

The authors acknowledge Faculty of Chemical Engineering Technology and University Malaysia Perlis for the financial support 


\section{REFERENCES}

Adilah Anuar/ Journal of Engineering and Science Research, 5(5) 2021, Pages: 01-06

[1] Azadpour N., Bahmani M., Hassanzadazar H., M. Rafieian-Kopaei, and Naghdi N. (2016). Antimicrobial effect of Ginger (Zingiber officinale) and mallow (Malva sylvestris) hydroalcholic extracts on four pathogen bacteria. Der Pharm. Lett., 8, 181-187

[2] Han Y. A. (2013). Anti-inflammatory effects of the Zingiber officinale roscoe constituent 12 dehydrogingerdione in lipopolysaccharide stimulated Raw 264.7 cells. Phyther. Res., 27, 1200-1205.

[3] Benzie I. F. F and Wachtel-Galor S.(2011). Herbal medicine: biomolecular and clinical aspects. CRC press

[4] Zhang Y., Liu X., Wang Y., Jiang P., and Quek S. (2016).Antibacterial activity and mechanism of cinnamon essential oil against Escherichia coli and Staphylococcus aureus. Food Control, 59, 282-289

[5] Nile S. H. and Park S. W. (2015). Chromatographic analysis, antioxidant, antiinflammatory, and xanthine oxidase inhibitory activities of ginger extracts and its reference compounds. Ind. Crops Prod., 70,238-244

[6] Citronberg J. (2013). Effects of ginger supplementation on cell-cycle biomarkers in the normal-appearing colonic mucosa of patients at increased risk for colorectal cancer: results from a pilot, randomized, and controlled trial. Cancer Prev. Res., 6, 271-281

[7] Kumar N. V. , Murthy P. S., Manjunatha J. R., and Bettadaiah B.K. (2014). Synthesis and quorum sensing inhibitory activity of key phenolic compounds of ginger and their derivatives. Food Chem., 159,451-457

[8] Ho S. C. , Chang K. S., and Lin C. C. (2013). Antineuroinflammatory capacity of fresh ginger is attributed mainly to 10-gingerol. Food Chem.,141, 3183-3191

[9] Akinyemi A. J. (2015) . Effect of dietary supplementation of ginger and turmeric rhizomes on angiotensin-1 converting enzyme (ACE) and arginase activities in L-NAME induced hypertensive rats. J. Funct. Foods, 17, 792-801.

[10] Suk S. (2017). Gingerenone A, a polyphenol present in ginger, suppresses obesity and adipose tissue inflammation in high fat diet fed mice. Mol. Nutr. Food Res., 61,1700139.

[11] Wei C. K. (2017). 6-paradol and 6-shogaol, the pungent compounds of ginger, promote glucose utilization in adipocytes and myotubes, and 6paradol reduces blood glucose in high-fat diet-fed mice. Int. J. Mol. Sci.,18, 168, 2017.

[12]Walstab J. (2013). Ginger and its pungent constituents non-competitively inhibit activation of human recombinant and native 5-HT3 receptors of enteric neurons. Neurogastroenterol. Motil., 25,439

[13] Townsend E. A., Siviski M. E., Zhang Y., Xu C., Hoonjan B., and Emala C. W. (2013).Effects of ginger and its constituents on airway smooth muscle relaxation and calcium regulation. Am. J. Respir. Cell Mol. Biol., 48,157-163

[14] Celli G.B. , Ghanem A., and Brooks M. S. L. (2015).Optimization of ultrasound-assisted extraction of anthocyanins from haskap berries (Lonicera caerulea L.) using Response Surface Methodology. Ultrason. Sonochem., 27: 449-455

[15] Anand S. P. and Sati N. (2013) .Artificial preservatives and their harmful effects: looking toward nature for safer alternatives. Int. J. Pharm. Sci. Res., 4,2496, 2013.

[16] Do Q. D. (2014). Effect of extraction solvent on total phenol content, total flavonoid content, and antioxidant activity of Limnophila aromatica. J. Food Drug Anal., 22, 296-302,

[17] Medina-Torres N., Ayora-Talavera T., EspinosaAndrews H., Sánchez-Contreras A., and Pacheco N. (2017). Ultrasound assisted extraction for the recovery of phenolic compounds from vegetable sources.Agronomy, 7, 47

[18] Murphy A., Norton E., Montgomery F., Jaiswal A. K., and Jaiswal S. (2020). Ultrasound-Assisted Extraction of Polyphenols from Ginger (Zingiber officinale) and Evaluation of its Antioxidant and Antimicrobial Properties. J Food Chem Nanotechnol, 6,88-96. 